\title{
Ontología política spinoziana: materialismo y potencia de la multitud
}

\author{
Spinozian politic ontology: materialism \\ and power of multitude
}

\author{
Abraham RuBín \\ Universidad Nacional de Educación a Distancia
}

Recibido: $16-02-2011$

Aceptado: 04-10-2011

\section{Resumen}

En este artículo trato de desarrollar puntos de confluencia entre el pensamiento ontológico de Spinoza y su visión política, utilizando para ello ciertos aspectos de la ética, como la concepción del deseo.

A pesar de las diversas interpretaciones al respecto y asumiendo la existencia de "varios Spinoza", el que yo desarrollaré aquí será el de un pensador materialista con una fuerte tendencia hacia el inmanentismo, características que serán la base sobre la que se podrá sustentar en un paso posterior una construcción política que busque la autonomía de un nuevo sujeto colectivo, la multitud.

Quizás no sea del todo ineficaz en la época contemporánea tender puentes hacia autores con visiones políticas novedosas en su época, que lucharon contra la tendencia dominante de su tiempo, con el fin de comprobar si podemos aprender algo de ello para aplicarlo a nuestro momento histórico.

Palabras clave: materialismo, multitud, potencia, Spinoza.

\begin{abstract}
In this article I try to develop points of confluence between Spinoza's ontological thought and his political vision, and I use for this purpose the ethic's concepts of desire.
\end{abstract}


Assuming the multiple interpretations in the matter I will develop a conception which thinks Spinoza like a materialistic and immanent thinker, characteristics on which it will be possible sustain a political construction that looks for the autonomy of a new collective subject, the multitude.

Nowadays, I believe that it is interesting to recover authors with new political visions in their epoch, which they fought against the dominant trend, in order to verify their possible implementation now.

Keywords: materialism, multitude, power, Spinoza.

\section{Introducción}

El objetivo que se busca en este artículo es reflexionar sobre las vías de confluencia del pensamiento ontológico con una posible construcción ético-política en el pensamiento spinoziano, utilizando para ello conceptos fundamentales en su proceder teórico, como los de potencia y deseo, y buscar su unión con aquellos de carácter propiamente político, como el de multitud.

A pesar de las diversas interpretaciones al respecto y asumiendo la existencia de "varios Spinoza", el que desarrollaremos aquí será el de un pensador materialista con una fuerte tendencia hacia el inmanentismo, características que serán la base sobre la que se podrá sustentar en un paso posterior una construcción política que busque la autonomía de un nuevo sujeto colectivo, la multitud.

Uno de los autores que más ha tratado esta conexión ha sido Antonio Negri, y a él especialmente seguiremos en este camino, sin renunciar a apelar a otros autores de concepciones teóricas distantes que puedan dar luz al debate que nos ocupa, esto es, la interrogación sobre la posibilidad de llevar a cabo un pensamiento ontológico inmanente y materialista del que se pueda consecuentemente concluir una concepción política democrática, plural y horizontal. Además de Negri, también Gilles Deleuze se tornará relevante en este terreno, el de apuntalar una ontología que parta de la univocidad del ser spinoziano, entregándole la posibilidad de existir a una teoría de la potencia que cristalice en el deseo de la multitud.

Quizás no sea del todo ineficaz en la época contemporánea tender puentes hacia autores con visiones políticas novedosas en su época, que lucharon contra la tendencia dominante de su tiempo, con el fin de comprobar si podemos aprender algo de ello para aplicarlo a nuestro momento histórico. 


\section{El pensamiento ontológico spinoziano en relación al materialismo}

\subsection{La substancia inmanente}

Es un lugar común de encuentro el asumir que Spinoza desarrolla la consideración de que la realidad global en su conjunto no es más que una Substancia única, llamada Dios o la Naturaleza. Martial Gueroult considera que ya en el Tratado breve Spinoza se propone la unidad de Dios y la Naturaleza por medio de los conceptos de causa sui y de causa inmanente y su identidad por la identificación de los atributos de Dios y los atributos constitutivos de la Naturaleza. ${ }^{1}$ Citando el apéndice geométrico del Tratado breve Gueroult concluye que «la Naturaleza es Dios no sólo porque (como en el diálogo) es su modo y la causa divina le es inmanente, ni tampoco porque todas sus substancias están integradas en el Ser infinitamente infinito que causa él mismo, sino porque se produce ella misma en todos los géneros infinitos que la constituyen». ${ }^{2}$ A su vez, desde la proposición VIII de la Ética en la que Spinoza afirma que «no existe más que una única substancia con el mismo atributo (por la Proposición 5) y el existir pertenece a su naturaleza (por la Proposición 7)» a la XVIII en la que dice que «Dios es causa inmanente pero no transitiva de todas las cosas», pasando por la XIV en la que advierte que «no puede darse ni concebirse substancia alguna excepto Dios», Spinoza va reduciendo una supuesta pluralidad -o al menos dualidad-inicial de substancias a la Substancia única. ${ }^{3}$ Este es el primer punto desde el que nos podemos apoyar para decir que esta totalidad única implica un rechazo de la creencia en una substancia trascendente y, de este modo, al no haber trascendencia el campo de acción se limita exclusivamente a lo terrenal.

Es importante dejar esto claro para poder comprender el papel que Spinoza le da a la concepción de Substancia como causa sui, causa de sí misma y de todo lo creado. Con Spinoza, la idea de trascendencia es sustituida por la de inmanencia, de tal manera que Dios se concibe en el mundo. Dios es la causa inmanente de todas las cosas, y por eso todo lo que es, es en Dios. «Tomada en su sentido único y en su única modalidad, la causa es esencialmente inmanente, es decir, permanece en sí para producir (en oposición a la causa "transitiva") y el efecto tampoco sale de ella (por oposición a la causa emanativa». 4

Dios, como causa inmanente, es entonces causa eficiente del mundo, causa activa por excelencia, que permanece idéntica en un todo, aunque quepa distinguir momentos en la producción. "Ante nosotros, ahí, la naturaleza: despliegue de

\footnotetext{
1 Martial Gueroult. Spinoza, Dieu. Paris: Aubier Montaigne, 1974, p. 479.

2 Op. Cit., p. 84.

3 Baruch Spinoza. Ética. Madrid: Alianza, 1987, p. I, prop. II y VIII, pp. 48 y 51-55.

${ }^{4}$ Carl Gebhardt. Spinoza. Buenos Aires: Losada, 1977, p. 50.
} 
potencia autónoma infinita. Nada en ella sabe de sentidos o finalidades; sólo libertad absoluta de la absoluta libertad inmanente». 5

En la proposición XXXIV de la primera parte de la Ética, Spinoza realiza una declaración que se tornará fundamental para todo lo que viene a continuación: «La potencia de Dios es su esencia misma». ${ }^{6} \mathrm{Y}$, más adelante, «La potencia de Dios no es otra cosa que la esencia activa de Dios, y, por tanto, nos es tan imposible concebir que Dios no actúa como que Dios no existe». ${ }^{7}$

M. Gueroult propone que en Dios no sólo hay un panteísmo (Dios está en todas las cosas), sino también un panenteísmo (todas las cosas están en Dios), los dos se implican mutuamente y acaban por coincidir:

La diferencia entre el panenteísmo y el panteísmo reside en que el primero es una propiedad necesaria de la esencia de Dios y el segundo es una propiedad inmediata no de su esencia, sino de su causalidad. Por lo primero todas las cosas son inmanentes a Dios; por lo segundo Dios será concebido como causa inmanente de las cosas que produce. ${ }^{8}$

Spinoza habla del Dios inmanente, ligado al mundo y constituyente de la vida del mundo. Dios es inmanente no sólo a sí mismo sino también a todas las cosas. Con esta teoría rompe Spinoza la dicotomía mundo y Dios como realidades separadas para establecer la unidad mundo-Dios, en la que Dios no es ajeno ni extraño al mundo, sino la propia actividad del mismo.

Según el Axioma I de la primera parte de la Ética, lo real se divide, por una parte, en la substancia (que es por sí) y los atributos, y por otra parte, en los modos (que son en otra cosa). «Lo que es, o es en sí, o en otra cosa». ${ }^{9}$

Esta división también está contemplada en la distinción que hace Spinoza entre Natura naturans (Dios) y Natura naturata -serie de efectos que constituyen el mundo natural:

Quiero explicar aquí (o más bien advertir) qué debe entenderse por Naturaleza Naturante, y qué por Naturaleza Naturada. Pues creo que ya consta, por lo anteriormente dicho, que por Naturaleza naturante debemos entender lo que es en sí y se percibe por sí, o sea, los atributos de la substancia que expresan una esencia eterna e infinita, esto es, Dios, en cuanto considerado como causa libre. Por naturaleza naturada, en cambio, entiendo todo aquello que se sigue de la necesidad de la naturaleza de Dios, o sea, de cada uno de los atributos de Dios, esto es, todos los modos de los atributos de Dios, en cuanto considerados como cosas que son en Dios, y que sin Dios no pueden ser ni concebirse. 10

\footnotetext{
6 Baruch Spinoza. Ética. Op. Cit., p. 94.

7 Op. Cit., p. II, prop. III, p. 114.

8 Martial Gueroult. Spinoza, Dieu. Op. Cit., p. 222.

9 Baruch Spinoza. Ética. Op. Cit., p. I, ax. I, p. 47.

10 Op. Cit., p. I, esc., prop. XXIX, pp. 83-84.
} 
Si asumimos la potencia de Dios, y llevamos la idea del Dios inmanente hasta el final, tal vez podamos comprender la unidad Mundo-Dios como el núcleo de actividad donde todo se produce. Es decir, dentro de la distinción de Natura Naturans y Natura Naturata, tendríamos el aspecto productor -Natura Naturans-, y por otra parte, el aspecto de lo producido-Natura Naturata-. Asimismo, por el concepto de inmanencia, lo productor y lo producido actuarían al mismo nivel, es decir, la producción la efectúa una causa inmanente y no transitiva, el efecto se produce sobre la misma causa y no en ningún lugar fuera de la misma.

Ya que no hay trascendencia en el acto causal, la Naturaleza (Mundo-Dios) ejerce su acción sobre sí misma, y es en este punto donde cobra sentido el entrelazamiento entre totalidad e inmanencia, desdoblado a su vez en el papel activo -productor-y el pasivo -producido.

De este modo, y siguiendo lo previsto en la proposición XXXIV de la primera parte de la Ética, ${ }^{11}$ se identifica la potencia de Dios, es decir, su actividad, su creatividad, con su esencia, es decir, con su propia naturaleza. Y, al mismo tiempo, podemos identificar el principio productor con aquello producido, afirmando la inmanencia y rechazando toda trascendencia divina.

Desde estos presupuestos es desde los que autores como Antonio Negri o Gilles Deleuze podrán construir una idea libertadora que sacarán de Spinoza, como más adelante veremos.

\subsection{EI ser como potencia y producción}

Partiendo de lo que hemos dicho anteriormente, el concepto de potencia remitiría al de producción. Por ello algunos autores entenderán que en Spinoza no podemos nombrar al ser sino en términos de producción.

Alexandre Matheron nos ofrece unas palabras que concluyen esta visión:

Se puede también hablar de Dios (como lo ha hecho Spinoza y como desde su propio punto de vista tiene todas las razones para hacerlo) para designar esa actividad productiva inmanente a las cosas, esta productividad infinita e inextinguible de toda la naturaleza, pero a condición de no olvidar lo que se quiere decir con ello: la naturaleza «naturante» es la naturaleza en tanto que naturante, la naturaleza considerada en su aspecto productor, aspecto aislado por abstracción; y la naturaleza «naturata» o los modos, son las estructuras que se dan al desplegarse, la naturaleza en tanto que naturata; pero en realidad no hay más que individuos más o menos compuestos, cada uno de los cuales (naturante y naturato a la vez) se esfuerza por producir todo lo que puede, y por producirse y reproducirse a sí mismo produciendo todo lo que puede: la ontología concreta comienza con la teoría del conatus. ${ }^{12}$

11 Op. Cit., p. 94.

12 Alexandre Matheron. "Prefacio". En Antonio Negri. L 'anomalie sauvage. Paris: PUF, 1982, p. 20. 
Aquí podemos ver cómo Matheron procura huir de cualquier tipo de interpretación jerárquica de la distinción substancia-atributos-modos, basándose en la inmanencia. La Naturaleza llamada naturante (como substancia y causa) y la Naturaleza llamada naturada (como efecto y modo) se entrelazan en vínculos de una mutua inmanencia; por una parte, la causa permanece en sí misma para producir; por otra, el efecto o el producto permanecen en la causa. 13

El mundo no es sino potencia y todo misterio se encuentra en su interior, nunca en una vía externa al mismo. Sólo la ignorancia de la causalidad natural y de sus poderes insospechados conduce a suponer causas finales y extranaturales para explicar lo que es sólo Naturaleza. En palabras de Spinoza:

A partir del hecho de que el poder por el que existen y actúan las cosas naturales, es el mismísimo poder de Dios, comprendemos con facilidad qué es el derecho natural. Pues, como Dios tiene derecho a todo y el derecho de Dios no es otra cosa que su mismo poder, considerado en cuanto absolutamente libre, se sigue que cada cosa natural tiene por naturaleza tanto derecho como poder para existir y para actuar. ${ }^{14}$

Desde el inmanentismo podemos ver cómo si la potencia es la esencia de la Substancia, alguna variación de la misma será la esencia del modo. Por ello Spinoza afirma que la esencia humana, es un desarrollo de la potencia, es decir, un deseo.

Al identificar ser con potencia, o dicho de otra forma, al asumir que la esencia del ser es actividad, es desde donde podemos entender la tesis de Negri de que el ser se constituye activamente, por lo que no es algo cerrado sino algo que siempre está en proceso de apertura y despliegue, algo que siempre se está liberando. ${ }^{15}$

Es, asimismo, apoyándonos en estas identificaciones cómo desde el inmanentismo podremos desembocar en el concepto de materialismo como algo defendible en Spinoza, entendiéndolo precisamente como algo derivado del inmanentismo, como afirmación de la univocidad radical de todo lo que es, en una concepción que no reconoce dualidades ni escisiones, tampoco en lo tocante a materia y espíritu. Así, cuando nos refiramos al materialismo spinoziano no lo haremos desde una visión de la materia como aquello de lo que se deduce todo lo demás, sino como una concepción que incluye en su interior, sin contradicciones, lo material y lo espiritual, lo divino y lo humano, la substancia y los modos, como parte del mismo conjunto. 16

13 Baruch Spinoza. Ética. Op. Cit., p. I, esc., prop. XXIX, pp. 83-84.

14 Baruch Spinoza. Tratado político. Madrid: Alianza, 1986, p. 85. Cursiva nuestra para indicar que A. Domínguez traduce "potentia" por "poder", por lo que de aquí en adelante corregiremos dicho término y asumiremos el de "potencia".

15 Antonio Negri. La anomalía salvaje. Barcelona: Anthropos, 1993, passim.

16 Montserrat Galcerán. Deseo (y) libertad. Una investigación sobre los presupuestos de la acción colectiva. Madrid: Traficantes de sueños, 2009, passim. 
Por tanto sólo hay naturaleza, y dentro de la misma, y como parte de ella, los seres humanos, a quienes habrá que interrogar sobre sus formas de asociación, es decir, sus sociedades, para comprender su relación natural con la substancia.

\subsection{La univocidad del ser}

La proposición XVIII - «Dios es causa inmanente, pero no transitiva, de todas las cosas»- también es el punto de partida para una concepción unívoca del ser. Desde el inmanentismo podemos postular una concepción que entienda el ser como la noción más universal de todas y, en consecuencia, común a todo lo que es. El ser se diría de la misma manera para todos los entes.De este modo, si el ser es unívoco y su potencia se despliega sobre un plano inmanente, el supuesto panteísmo spinoziano podría superarse sólo abriéndose de nuevo. Pero panteísmo es una plenitud de ser, por lo que su reapertura no puede ser más que una construcción de ser, una autoconstitución -tal es la tesis de Negri-:

La forma que tenemos de ver la relación entre el ser unívoco y el ser como potencia es a partir de una tensión ontológica y epistemológica, es decir, la concepción del ser es unívoca en lo ontológico y equívoca en lo epistemológico [...]. Así que esta tensión sólo se puede resolver en la práctica de la potencia. ${ }^{17}$

En palabras de Spinoza, «las percepciones claras y distintas, que nosotros formamos, sólo dependen de nuestra naturaleza y de sus leyes determinadas y fijas; es decir, que sólo dependen de nuestra potencia absoluta».18 La existencia es, así, la espontaneidad del ser. Y, consecuentemente, a esta espontaneidad de la existencia le corresponde una espontaneidad en la potencia. ${ }^{19}$

Basándonos en esta apertura de la existencia y en el ser como autoconstitución - ambos dados a partir de la idea de inmanencia- es desde donde podemos introducir la noción de materialismo en Spinoza.

\subsection{Spinoza en la historia materialista}

Para ello, y creando una genealogía, introduciremos a Spinoza en la historia del materialismo desde Giordano Bruno siguiendo la caracterización que de ello hace Bloch, ${ }^{20}$ para quien lo fundamental de esta tradición es una

\footnotetext{
17 Antonio Negri. La anomalia salvaje. Op. Cit., p. 90.

18 Baruch Spinoza. Correspondencia. Madrid: Alianza, 1988, p. 256.

19 Cfr. Antonio Negri. La anomalía salvaje. Op. Cit. passim.

20 Cfr. Francisco José Martínez. Materialismo, idea de totalidad y método deductivo en Espinosa. Madrid: UNED, 1988, pp. 44-51.
} 
naturalización iniciada por Avicena (según la cual toda la materia tiene forma y viceversa), la cual progresó posteriormente con Avicebrón, hasta producir el concepto de una 'materia universalis'; mostrando acto seguido en Averroes a la materia como dotada de eterno movimiento interior y uniformemente viva: en calidad de 'natura naturans' sin necesidad de un Dios-Nous ni fuera ni por encima de ella. ${ }^{21}$

Según Bloch, desde el concepto de materia en Aristóteles hasta su recepción en la llamada izquierda aristotélica se dan dos transformaciones fundamentales para entender la tradición que reivindicamos aquí para Spinoza. La primera de ellas se refiere a la materia como algo activo, carácter que no está en Aristóteles y que es clave para unir con la idea de producción y potencia. La segunda de ellas trata de «admitir que no existe una posibilidad totalmente realizada, lo que nos lleva a admitir un horizonte de posibilidad nunca alcanzado».22 Así se puede concebir un progreso continuo desde la materia -línea marxista que desarrolla el propio Bloch-o, al menos, una apertura continua de la que se podría concluir la concepción de ser como autoconstitución -visión de Negri-. Esta última remitiría a «un horizonte ontológico completamente unívoco $[\ldots]$, una dinámica constitutiva $[. .$.$] ; [y] una$ dimensión colectiva, social, de la práctica ontológica». ${ }^{23}$ Es decir, desde la concepción unívoca del ser también podemos llegar al materialismo y a la apertura ontológica constante, que nos lleva hacia una colectividad productiva de la misma.

Esta univocidad del ser supone el rechazo explícito de otras concepciones sobre él, en concreto la analogía y toda su tradición. De hecho Deleuze interpreta en Spinoza una triple univocidad: de los atributos, de la causa y de la modalidad, oponiéndose así a las concepciones modernas que se supone comparten tradición con Spinoza, y que pasan así a ser desplazadas por nuestro autor, que se convierte en excepción a su tiempo. ${ }^{24}$

Por otra parte, Tosel, 25 en su estudio sobre Spinoza enumera las características de las que se puede colegir el materialismo spinoziano:

- Anticreacionismo.

- Negación del finalismo y la teleología, en la que los fines responden a su situación material e inmanente y no trascienden los intereses de la relación de los modos entre sí y con la substancia.

- Optimismo basado en la confianza depositada en el poder de la razón.

\footnotetext{
21 Ernst Bloch. Avicena y la izquierda aristotélica. Madrid: Ciencia Nueva, 1966, p. 29.

22 Francisco José Martínez. Materialismo, idea de totalidad y método deductivo en Espinosa. Op. Cit., p. 45.

23 Antonio Negri. L'anomalie sauvage. Op. Cit., p. 182.

24 Cfr. Gilles Deleuze. Spinoza. Filosofia práctica. Madrid: Tusquets, 1984, p. 67.

25 Cfr. André Tosel. Du materialisme de Spinoza. Paris: Kimé, 1994, passim.
} 
- Relevancia predominante del deseo y el placer incluso en la concepción científica, que se supedita a lograr los objetivos de bienestar y felicidad del ser humano.

- «Naturalismo en tanto que antiantropomorfismo y antropocentrismo radicales».

- Una concepción ética separada de la moral y religión de su tiempo, es decir, basada -como la ciencia- en el bienestar del ser humano, en cuanto poseedor de un cuerpo y una mente productivas con ciertas potencialidades que puede desarrollar al margen de un deontologismo.

Sin embargo, en opinión de Giancotti, no podemos llamar materialista a Spinoza porque en él se mezclan elementos materialistas e idealistas. ${ }^{26}$ En concreto, Spinoza no identifica realidad y materia, pues no entiende la Naturaleza como «cierta masa o materia corpórea»,27 sino que ésta también contiene los pensamientos, modos y atributos que componen la Substancia. Así, existe entre ellos un total paralelismo, careciendo de jerarquía.

Por tanto, si se quiere esquivar la objeción de Giancotti es preciso mantener una concepción materialista que vaya más allá del concepto de materia clásico y sea pluralista, reconociendo varios niveles dentro de la propia materia entre los que se halle el pensamiento. Con esto, y haciendo hincapié en el inmanentismo e univocidad del ser, sí podemos llegar a una concepción materialista de Spinoza.

En esta visión, y con respecto a la substancia, el atributo funciona como un intermediario por medio del cual lo absoluto se dirige hacia el mundo y se organiza en él. Por ello podemos decir que el ser se funda sobre cada cosa continuamente, una y otra vez, repitiendo la potencia de la misma sobre el horizonte de todas ellas. ${ }^{28}$

Al unificarse la materia y el pensamiento dentro de la concepción materialista, y haciéndolo asimismo los dos atributos - «el Pensamiento es un atributo de Dios, o sea, Dios es una cosa pensante» hacia «La Extensión es un atributo de Dios, o sea, Dios es una cosa extensa»-29 se crea una dimensión del mundo que no es jerárquica, sino plana y lisa. Este momento es clave pues la univocidad del ser y esta disolución de toda mediación entre los atributos y la substancia, lleva a poner en primer plano la idea de potencia. Y con ello lo abstracto se vuelve concreto.

Así llegamos a la posición ontológica buscada por Negri -y por Deleuze-, aquella que da la posibilidad de retomar de ella repercusiones que se puedan aplicar en un campo ético-político. La ontología, entonces, podría convertirse en aquello que fundamenta la condición ética para convertirse en ontología constitutiva, para ser

\footnotetext{
26 Cfr. Emilia Giancotti. Studi su Hobbes e Spinoza. Napoli: Bibliopolis, 1995, passim.

27 Baruch Spinoza. Correspondencia. Op. Cit., p. 387.

28 Cfr. Antonio Negri. La anomalía salvaje. Op. Cit., pp. 107-155.

29 Baruch Spinoza. Ética. Op. Cit., pp. 112-113.
} 
recorrida por la acción ética de una subjetividad dispuesta a hacerse cargo de la misma.

\section{La ética spinoziana como despliegue ontológico}

\subsection{El sujeto ético-político}

Esta configuración metafísica podría ser usada en la acción ético-política de una subjetividad, creando de este modo una ontología política. Y es un motivo para ver la ruptura esencial que Spinoza hace con su tiempo, esta vez a tenor del concepto de sujeto -fundamental para introducirnos en la concepción spinoziana de ética y política:

El sujeto clásico, visto desde un punto de vista ético y político, se refiere respectivamente al individuo - conducta humana individual-y a la comunidad - pólis, pueblo o nación, es decir, una organización humana colectiva. Por tanto, en principio el sujeto de la ética son los individuos y el de la política las colectividades. ¿Son estos también el sujeto ético-político en Spinoza? Para determinarlo no se debe olvidar que la ontología de Spinoza parte de una postura metafísica que elimina todo antagonismo o dualismo, incluido el dualismo entre ética y política aquí mencionado. De hecho, Spinoza tratará de eliminar -o declarar irreal o ilusoria- la escisión entre individuo y sociedad integrándolos en una unidad acorde con su filosofía de la substancia. Esta integración es contraria a las tendencias éticas y políticas de su tiempo, entroncando así Spinoza tanto con el pasado griego como con el futuro hegeliano -en este exclusivo sentido.

El tiempo de Spinoza arranca del Renacimiento y de su concepción del individuo en torno a varios ejes:

- En el arte, con la valoración del genio creativo, concepción clásica del Renacimiento.

- En la política, donde se concibe al individuo con anterioridad natural al estado social. De aquí surgen las concepciones clásicas del pacto, tanto en Hobbes, como en Locke o Rousseau.

- En la ética, donde a partir de Maquiavelo ésta se separa de la religión, es decir, el individuo se libera de los candados eclesiásticos y de una autoridad suprema sobrenatural.

En este contexto las teorías sitúan al individuo como sujeto o referente último tanto de la política como de la ética. Pero aquí surgen dos orientaciones: 
- Los que consideran que el individuo posee derechos previos al Estado (iusnaturalismo).

- Los que consideran al individuo pre-estatal un ser egoísta y malvado (Maquiavelo, Hobbes, etc.). Éstos, como contrapartida, justifican un poder estatal absoluto.

En cualquiera de los dos casos el Estado limita la libertad natural individual. En cambio Spinoza quiere un Estado que aumente o, por lo menos garantice esa potencia de la libertad individual, pero sin caer ni en el egoísmo ni en el absolutismo. Teóricamente Spinoza pretende conseguirlo concibiendo un sujeto nuevo que para él es el sujeto colectivo, pero no entendido como una realidad social en la que se diluye el individuo -concepción de la pólis griega-, sino como entidad colectiva que aumenta la tendencia natural e individual de sus componentes, es decir, el conatus de cada modo-individuo. En palabras de Spinoza:

Entiendo por cosas singulares las cosas que son finitas y tienen una existencia limitada; y si varios individuos cooperan a una sola acción de tal manera que todos sean a la vez causa de un solo efecto, los considero a todos ellos, en este respecto, como una sola cosa singular. ${ }^{30}$

La cristalización de este sujeto, como veremos, sucede en el concepto de multitudo y para llegar hasta él debemos en primer lugar profundizar en la concepción individual spinoziana, es decir, en su teoría del modo.

\subsection{Conatus, deseo y potencia}

\subsubsection{La afección}

Spinoza define los modos como afecciones de la substancia, ${ }^{31}$ y el afecto lo entiende como

las afecciones del cuerpo, por las cuales aumenta o disminuye, es favorecida o perjudicada, la potencia de obrar de ese mismo cuerpo, y entiendo, al mismo tiempo, las ideas de esas afecciones.

Así pues, si podemos ser causa adecuada de alguna de esas afecciones, entonces entiendo por "afecto" una acción; en los otros casos, una pasión. 32

\footnotetext{
30 Op. Cit., p. 111.

31 Op. Cit., p. I, def. V, p. 47.

32 Op. Cit., p. III, def. III, 193.
} 
Al realizar una lectura de la Ética podemos observar que se consideran 48 afectos, de los cuales sólo tres son fundamentales: el deseo, la tristeza y la alegría. ${ }^{33} \mathrm{El}$ deseo es el apetito consciente de sí mismo, «...la esencia misma del hombre, es decir, un esfuerzo por medio del cual trata el hombre de perseverar en su ser».34 Pero este deseo puede tener aspectos distorsionados o destructivos, que nacen de las pasiones tristes que producen un pasaje a una menor perfección o, por el contrario, pueden permitir desarrollar la potencia por medio de las pasiones alegres que conducen a una mayor perfección. 35

Así, el deseo es un grado de potencia, parte de la potencia productiva de la Substancia que se vierte y despliega por todo lo creado, por todo lo real. Porque toda potencia es acto, la potencia no puede separarse de un poder de afección. La esencia del modo es a su vez grado de potencia, parte de la potencia divina, es decir, en lenguaje deleuziano, parte intensiva o grado de intensidad.36 Por esta razón, el deseo es tendencia a mantener y abrir al máximo la capacidad para ser afectado, 37 sabiendo que habrá que distinguir aquello que nos hace bien, que nos causa alegría, que aumenta nuestra potencia, de lo que la disminuye.

\subsubsection{Deseo y conatus}

Llegamos pues al concepto de deseo, definido asimismo como el conatus consciente de sí mismo conforme a uno u otro afecto. Por ello el deseo es siempre deseo de algo determinado -en consonancia con la definición spinoziana. ${ }^{38}$

Se comprende por qué, a partir del momento en que el modo existe, su esencia en cuanto grado de potencia queda determinada como conatus, o sea como esfuerzo o tendencia. ${ }^{39}$ Spinoza lo dice de esta forma:

El esfuerzo [conatus], con que cada cosa intenta perseverar en su ser, no es nada distinto de la esencia actual de la cosa misma. ${ }^{40}$

De este modo el deseo es el apetito con conciencia de sí mismo, y el conatus el elemento esencial, el motor permanentemente activo que es en sí mismo acto, dato, emergencia consciente de lo existente no finalizado. ${ }^{41}$

33 Op. Cit., p. III, prop. XI, p. 207.

34 Op. Cit., p. IV, prop. XVIII, pp. 305-308.

35 Op. Cit., pp. 263-264.

36 Gilles Deleuze. Spinoza. Filosofía práctica. Op. Cit. pp. 120.

37 Baruch Spinoza. Ética. Op. Cit., p. IV, prop. XXXVIII, p. 331

38 Op. Cit., pp. 262-263.

39 Gilles Deleuze. Spinoza. Filosofía práctica. Op. Cit. p. 121

40 Baruch Spinoza. Ética. Op. Cit., p. 204.

${ }^{41}$ Cfr. Gilles Deleuze. Spinoza et le probleme de l'expression. Paris: Minuit, 1968, pp. 197-213. Cit. en Antonio Negri. La anomalía salvaje. Op. Cit., p. 250. 
Por este camino es por el que podemos llegar a ver la cupiditas como punto de cristalización entre cuerpo y pensamiento, entre su conatus y su potencia, respectivamente. La cupiditas no es una relación, ni una posibilidad, sino una potencia ${ }^{42}$, es siempre un acto y refleja la potencia de crear y de comprender lo creado de la Substancia. Por ello es poder de afección e intensidad y la amplitud más grande posible del ser-afectado. Y cuando es consciente de sí misma conforme a un afecto, le llamamos "deseo".

Ya que los modos tienen como esencia una capacidad de abrirse al exterior, de entrar en relación con los otros modos y con otras relaciones de intensidad, podemos desplegar desde este punto la concepción puramente ética de Spinoza, que entronca con su ontología.

Deleuze explica el enlace ético extraordinariamente:

Experimentamos alegría cuando un cuerpo se encuentra con el nuestro y se compone con él, cuando una idea se encuentra con nuestra alma y se compone con ella, o por el contrario, tristeza cuando un cuerpo o una idea amenazan nuestra propia coherencia.

[...] El apetito no es más que esfuerzo por el que cada cosa se esfuerza en perseverar en su ser, cada cuerpo en la extensión, cada alma o cada idea en el pensamiento (conatus). Pero puesto que este esfuerzo nos empuja a diferentes acciones de acuerdo al carácter de los objetos con los que nos encontramos, tendremos que afirmar que está en cada instante determinado por las afecciones procedentes de los objetos. Estas afecciones determinantes son necesariamente la causa de la conciencia del conatus. ${ }^{43} \mathrm{Y}$ como las afecciones no pueden separarse del movimiento por el que nos conducen a una perfección mayor o menor (alegría o tristeza), según si la cosa con la que nos encontramos se compone con nosotros o, por el contrario, tiende a descomponernos, la conciencia aparece como el sentimiento continuo de este paso de más o menos, de menos o más, testigo de las variaciones y de las determinaciones del conatus en función de los otros cuerpos o de las otras ideas. 44

Vemos pues al conatus y a la potencia como claves para la producción del deseo, la capacidad de afección y, en fin, la configuración de una ética al margen de clichés y convencionalismos. Deleuze continúa de este modo:

Lo bueno tiene lugar cuando un cuerpo compone directamente su relación con la nuestra y aumenta nuestra potencia con parte de la suya, o con toda entera. Por ejemplo, un alimento. Lo malo tiene lugar, para nosotros, cuando un cuerpo descompone la relación del nuestro, aunque se componga luego con nuestras partes conforme a relaciones dis-

\footnotetext{
42 Op. Cit., p. 265.

43 Baruch Spinoza. Ética. Op. Cit., pp. 262-263.

44 Gilles Deleuze. Spinoza. Filosofía práctica. Op. Cit., pp. 29-31.
} 
tintas a las que corresponden a nuestra esencia, como actúa un veneno que descompone la sangre. [...] Se llamará bueno (o libre o razonable o fuerte) a quien, en lo que esté en su mano, se esfuerce en organizar los encuentros, unirse a lo que conviene a su naturaleza, componer su relación con relaciones combinables y, de este modo, aumentar su potencia. Pues la bondad es cosa del dinamismo, de la potencia y composición de potencias. Se llamará malo, o esclavo, débil, o insensato, a quien se lance a la ruleta de los encuentros conformándose con sufrir los efectos, sin que esto acalle sus quejas y acusaciones cada vez que el efecto sufrido se muestre contrario y le revele su propia impotencia. 45

\subsubsection{El sujeto colectivo y la potencia del deseo}

El punto de llegada de esta reflexión es la idea de sujeto colectivo spinoziano, partiendo de la configuración ética de la potencia y de la relación de los modos entre sí a partir de la misma. Spinoza dice:

Si dos se ponen mutuamente de acuerdo y unen sus fuerzas, tienen más potencia juntos y, por tanto, también más derecho sobre la naturaleza que cada uno por sí solo. Y cuantos más sean los que estrechan así sus vínculos, más derecho tendrán todos unidos. ${ }^{46}$

En esta cita vemos una primera aproximación a la relación entre derecho y potencia, o cómo individuos unidos tienen más derecho que por separado. Aunque el fundamento de esto viene en el Escolio de la proposición XVIII de la cuarta parte de la Ética, donde Spinoza afirma que la unión de dos individuos con una naturaleza enteramente igual produce un individuo doblemente potente que cada uno de ellos por separado. ${ }^{47} \mathrm{Y}$ de ahí infiere que «nada pueden desear los hombres que sea mejor para la conservación de su ser que el concordar todos en todas las cosas, de suerte que las almas de todos formen como una sola alma [...] y buscando todos a una la común utilidad».48

Esta idea de sujeto colectivo, individuo compuesto universal, es la que desarrollará en el Tratado Político, a la búsqueda de una comunidad universal, que no está dada de antemano, pero que representaría un esquema ontológico acorde con la Ética utilizando para ello el concepto de multitud.

En los casos en los que los individuos no tengan una naturaleza enteramente igual, estos pueden ser afectados de alegría o tristeza $-\mathrm{y}$ consecuentemente, unirse con más o menos potencia- según la potencia del individuo con el que se unan.

\footnotetext{
45 Op. Cit., pp. 34-35.

46 Baruch Spinoza. Tratado político. Op. Cit., p. 92.

47 Baruch Spinoza. Ética. Op. Cit., p. 307.

48 Ibid.
} 
Nuestro cuerpo se descompone en una relación con un cuerpo que disminuye nuestra potencia, sufriendo la afección-pasión de la tristeza. Por el contrario, cuando logramos composición con otro cuerpo y, así, aumentamos nuestra potencia en común, nos afecta la pasión de alegría. 49

Una de las finalidades buscadas será el de que uno de los picos más altos de composición entre cuerpos y, por tanto, de aumento continuo de potencia se alcance construyendo un sujeto colectivo cada vez más grande y potente, pero en el que no se diluyan las individualidades como tales: ese esquema es el que seguirá el concepto de multitud, que mostrará mejor que otros la alegría de la potencia en cuanto composición colectiva.

De todas formas, otro de los puntos a tener en cuenta es que la ética se va a separar de una moral, es decir, no va a haber una definición externa o universal a las acciones del ser humano para el bien o el mal, sino que todo va a ser referido a la afección individual y a la composición de fuerzas concreta que cada uno tiene en su intensidad. Es un principio de utilidad. Es decir, a cada uno le conviene una cosa u otra, sin reglas absolutas externas o trascendentes. Todo es inmanencia que refiere y enlaza las partes entre sí formando un todo que se llama Dios o la Naturaleza.

Por lo tanto, hablamos aquí de un derecho natural, que es idéntico a la potencia del modo e independiente de todo reino de fines.

Si la moral es un reino de deberes, vemos cómo la Ética es el reinado de la potencia, y por tanto, cómo toda acción ética tiene una base estrictamente ontológica.

No se compara lo existente con nada externo a ello, es decir, con nada trascendente -como podían ser los valores-, de lo que se concluye que no existe una axiología previa o exterior a los propios individuos o a la sociedad. Spinoza, por el contrario, realiza la simple constatación de lo que hay (lo bueno, lo malo), y además no lo define desde un punto de vista absoluto que valga para todos los seres humanos, sino desde la postura perspectivista de cada modo finito.

En este plano de identificación inmanentista y naturalista, Espinosa identificará: la relación ontológica (substancia/modo) con la relación epistemológica (esencia/propiedades) y con la relación física (causa/efecto). [...] Aplicando esto a la relación entre la Natura Naturans y la Natura Naturata, la primera, teniendo los aspectos de substancia, esencia y causa, y la segunda siendo los modos, las propiedades y los efectos, vemos que entre ellas hay lazos de mutua inmanencia. 50

Esta transformación lleva consigo una concepción distinta tanto del deseo, entendido ahora como activo y decisivo, repleto de actividades, como de la razón

\footnotetext{
49 En base a las definiciones de alegría y tristeza. Cfr. Op. Cit., p. 263.

50 Francisco José Martínez. Materialismo, idea de totalidad y método deductivo en Espinosa. Op. Cit., pp. 52-53.
} 
que conoce la causalidad presente entre las cosas, es decir, que las ve como efectos $\mathrm{y}$, por tanto, puede afirmar de ellas la potencia que tienen en su individualidad y en su conjunto, en las relaciones que pueden formar entre sí. 51

La potencia es el único horizonte metafísico posible y por ello sólo la ética -como ciencia de la liberación, de la constitución práctica del mundo- puede indagarlo de manera adecuada.

La liberación humana, a la que hemos llegado desde la ontología de la autoconstitución, inmanencia y univocidad del ser, y la teoría de la potencia, se realiza a lo largo del camino de la Ética. Por ello el deseo es ilimitado y para Spinoza no está penado:

El deseo, considerado en absoluto [...] es la misma esencia del hombre, en cuanto se la concibe como determinada de algún modo a hacer algo; y así, el deseo que brota de la razón, esto es [...], el que se engendra en nosotros en la medida en que obramos, es la esencia o naturaleza misma del hombre, en cuanto concebida como determinada a obrar aquello que se concibe adecuadamente por medio de la sola esencia del hombre [...]; así, pues, si ese deseo pudiera tener exceso, entonces la naturaleza humana, considerada en sí sola, podría excederse a sí misma, o sea, podría mas de lo que puede, lo cual es contradicción manifiesta, y, por ende, ese deseo no puede tener exceso. 52

Desde esa perspectiva puede Spinoza afirmar que no deseamos e intentamos algo porque sea bueno, sino que lo juzgamos bueno en la medida en que lo deseamos. Se pone en marcha así una ética radical, que no califica o descalifica la realidad, sino que la afirma, la intensifica, la compone, la construye. Ética adecuada a la ontología de la potencia y, por tanto, ética del esfuerzo de ser, de la acción, de la alegría y de la libertad; no del poder, ni del deber, ni de la ley. Dice Spinoza: «El derecho y la norma natural, bajo la cual todos los hombres nacen y viven la mayor parte de su vida, no prohíbe sino lo que nadie desea».53

Ahora bien, este es un punto conflictivo en Spinoza -y también en las interpretaciones que del mismo hacen Negri y Deleuze-, pues una de las claves del pensamiento spinoziano es la que parte de la consideración de la mens -y de su esencia, el conocimiento- 54 como encargada de controlar las afecciones. En el prefacio a la parte quinta de la Ética, Spinoza asegura que la potencia de la razón puede a los

51 Eugenio Fernández. «Articulación crítica de ontología y política en B. Spinoza». Revista de Filosofia [en línea]. $3^{\mathrm{a}}$ época, vol. IX, núm. 15, 1996. Madrid: Servicio Publicaciones UCM, http://revistas.ucm.es/fsl/00348244/articulos/RESF9696120097A.PDF, [Consulta: 20 de febr. 2009], ISSN: 1988-284x, passim.

52 Baruch Spinoza. Ética. Op. Cit., p. 354.

53 Baruch Spinoza. Tratado político. Op. Cit., p. 89.

54 Si nos ajustamos a la proposición XI de la p. II de la Ética. Baruch Spinoza. Ética. Op. Cit., pp. 125126. Peña traduce siempre mens por alma. 
afectos: «Mostraré ante todo la magnitud y características de su imperio [de la razón] sobre los afectos, en orden a regirlos y reprimirlos».55 Lo podemos ver asimismo en la proposición III de la misma parte, cuando Spinoza dice: «Un afecto que es una pasión deja de ser pasión tan pronto como nos formamos de él una idea clara y distinta. [...] Un afecto que es una pasión es una idea confusa». ${ }^{56}$ Es decir, la razón puede más que los afectos y es la tabla de salvación de aquel que se pierde en los mismos. La salvación, pues, la da el conocimiento. Pero, siguiendo el escolio de la proposición IV de la quinta parte, el conocimiento no implica la supresión de los afectos, sino su utilización racional. ${ }^{77}$ Es decir, lo que hace que el deseo no tenga exceso es el control previo que la razón -y, por tanto, el conocimientohace de los afectos, provocando que los deseos broten de ideas adecuadas. Por tanto, aquel que sin conocimiento se entrega a las pasiones no controla los afectos y su deseo sí puede ser desmedido. La relación razón-deseo se vuelve imprescindible y, sin embargo, es un punto de unión obviado en la interpretación negriana $-\mathrm{y}$ deleuziana.

Lo que queda en todo caso fuera de duda es que una parte importante del deseo es la construcción colectiva y la ampliación de la potencia de cada cual. Y esto ya es visión política.

\section{La consecuencia política}

\subsection{Disquisiciones en torno al pacto social}

En el Tratado teológico-político Spinoza comienza aceptando la explicación mediante el pacto social, destacando que el sentido que tiene es que expresa una racionalidad clara: la potencia de muchos unidos -y la organización que esto lleva consigo- es más útil para la comunidad que la dispersión individual. Pero no tiene más sentido que éste:

«El pacto no puede tener fuerza alguna, sino en razón de la utilidad, y [...] suprimida ésta, se suprime ipso facto el pacto y queda sin valor». 58 Por tanto, no es algo formal que se cumpla en todos los casos ni depende de ninguna voluntad general. De la misma manera se separa de un contrato irrevocable que se pueda colocar en contra de quien lo hace operativo en determinado instante. Pues el gobernante sólo posee el derecho de mandar en cuanto tiene la suprema potestad-condicionada por la sociedad. Si la pierde pasa directamente a quien previamente se la había entrega-

55 Op. Cit., p. 383.

56 Op. Cit., p. 389.

57 Op. Cit., pp. 390-391.

58 Baruch Spinoza. Tratado teológico-político. Madrid: Alianza, 1986, p. 336. 
do Y por ello el gobernante evita mandar que se realicen acciones absurdas pues dirigir según el dictamen de la razón va, incluso, en el propio interés de conservar el mando.

Sin embargo en el Tratado político Spinoza cambia. No utiliza el término «pacto» y se distancia de sus atribuciones. Seguramente lo hace por los peligros que se pueden derivar de la fundación del Estado, entendiendo éste como algo cerrado en sí mismo, completo y, por tanto, por la legitimidad que se le da al mismo, impidiendo cualquier tipo de cambio radical que vaya más allá de modificaciones insustanciales o reformas. Por el contrario, el proceso de constitución, en consonancia con la ontología del ser que hemos visto hasta aquí, debe ser continua, gradual y siempre permanecer abierta en pos de la liberación, lo que impide permitir una composición legítima per se en un acto fundacional. «Como en Ética [sic], la construcción política deriva de la conjunción natural de afectos e intereses que generan sentimientos comunes, con-sensos que la razón hace acuerdos firmes».59

Por tanto, se da un salto de un "tratado" a otro con respecto al contractualismo. En el Tratado político no hay transferencia de poder y, por tanto, la sociedad sólo puede establecerse mediante la constitución de una potencia colectiva, la potencia de la multitud, capaz de proteger a cada individuo sin quitarle su derecho. Esta constitución se opone al pacto de Hobbes, en el que el pacto es absoluto, no revocable y el soberano no entra dentro de las condiciones pactadas, pero también al pacto liberal -que pacta de manera revocable y en el que el soberano se mantiene dentro de las premisas del pacto- y al rousseauniano de la voluntad general, que en su afán colectivo elimina las individualidades y las diferencias.

La política, pues, se hace cargo de un flujo colectivo de potencias y derechos. Por eso el cuerpo colectivo formado es inmanente, es decir, la transferencia de poder que se da del individuo al sujeto colectivo no se hace en base a una instancia superior, sino que permanece en el mismo plano. Así, nos sirve la figura del flujo, tan utilizada por Deleuze, para ilustrar el modo en el que se realiza la distribución, la circulación continua a través de intensidades distintas que, con sus respectivas potencias, hacen que el flujo se personalice de una u otra forma, con más o menos potencia, pero siempre horizontal, sin posiciones jerárquicas dentro del mismo. 60

$\mathrm{Al}$ alejarse del pacto y de las condiciones formales, y manteniéndose en un plano de inmanencia, la única legitimación posible de la unión responde a los efectos que se realicen en la colectividad. El poder que salga de esta concepción tendrá que guiarse en torno a la constitución colectiva y dependerá siempre de la potencia de ésta, que cede el uso de su derecho, pero sigue siendo propietario del mismo.

\footnotetext{
59 Eugenio Fernández. «Articulación crítica de ontología y política en B. Spinoza». Op. Cit., pp. 121-122. 60 Gilles Deleuze. Spinoza. Filosofía práctica. Op. Cit., passim.
} 


\subsection{Constitución de la potencia de la multitud}

Este es el motivo por el que Spinoza defiende el derecho de resistencia y de rebeldía, y sostiene la libertad de pensamiento, en pos de salvaguardar la individualidad que deja surgir el sujeto colectivo, pero que depende de él.

La potencia de la multitud pasa a ser el poder constituyente de la política y se plasma decididamente en una concepción democrática, por ser la articulación más adecuada para ella. La expresión poder constituyente es clásica en Negri, y desde su visión es aquello que produce las normas constitucionales de todo ordenamiento jurídico y, por lo tanto es el sujeto de esta producción. Pero la potencia en la que se basa no se integra en el objeto producido sino que, como fuente, permanece extraña. Así, no se puede reducir al campo del derecho, a la constitución o al orden jurídico de una sociedad. No obstante, es en función del poder constituyente por lo que ellos crean. Entendiéndolo, pues, como poder omnipotente es la revolución misma, expansiva e ilimitada en el tiempo y el espacio. Pero la ciencia jurídica reduce su poder entendiéndolo como productor del derecho, como poder constituido. De este modo aquello que debe legitimar todo proceso jurídico queda atrapado en el propio sistema al que ha dado lugar, en este caso, el de la representación política. ${ }^{61}$

Por consiguiente, el poder en esta democracia radical sólo lo puede ejercer legítimamente la multitud, al igual que el derecho y las leyes. Es radical, pues su transferencia de poder se hace exclusivamente en virtud de la composición de fuerzas que se da en los flujos colectivos de potencias y derechos y que se gestiona desde los mismos sin referencia a nada externo, ni tan siquiera a un tipo de acumulación de poder en una instancia concreta, sea superior o simplemente individual. Así, la identificación que la multitud hace en su espectro político es siempre provisional y puede cambiar en cualquier momento, haciendo nuevas instituciones o constituyendo nuevas formas de organización. De esta manera, lo constituido nunca queda cerrado y completo sino que siempre está en construcción. Los ciudadanos de esta sociedad se comportan, pues, realmente como individuos iguales y libres que mantienen su colectividad por interés y deseo propios en la búsqueda de su felicidad. Y no es algo secundario ya que «el verdadero fin del Estado es, pues, la libertad».62

Es este un horizonte colectivo y materialista: a la individualidad no se vuelve ni como principio ni como valor, se vuelve simplemente como a un elemento de la estructura del ser que se despliega continuamente hacia la sociabilidad y por medio de ella.

En todo caso, la multitud tiene también sus peligros, ya que puede llegar en su constitución a ser masa, una masa cruel que resulte temible y pueda ser manipulada. Pero este peligro real no es una característica de la naturaleza de la multitud sino

61 Antonio Negri. El poder constituyente. Madrid: Libertarias/Prodhufi, 1994, pp. 11-13.

62 Baruch Spinoza. Tratado teológico-político Op. Cit., p. 411. 
una posibilidad a la que se puede llegar o una tendencia que se puede modificar. Aquí, por tanto, cobraría importancia la educación en la colectividad unida a la producción del deseo revolucionario -como por ejemplo, desarrollan Negri y Hardt en Multitud o Deleuze y Guattari en El Anti-Edipo y Mil mesetas.

Es la construcción ontológica de la potencia de la Naturaleza la que consigue desplegar sus raíces hacia una nueva disposición del espacio político, en la búsqueda continua de la construcción libre. De forma que liberar y construir la potencia de la multitud se convierte en la praxis ético-política por excelencia, y la democracia radical un buen camino para efectuarla.

La reivindicación del mundo de los modos plantea inmediatamente el problema de la realidad de la imaginación y de la libertad. La imaginación es ilusión, pero esta ilusión permite la apertura y la construcción de alternativas, es decir, en lo que se refiere a actividad política se transforma en índice de un proceso de constitución. Así pues, la libertad puede constituirse dentro de los dominios del reino de la imaginación como el único ser que está en vías de realizarse.

La imaginación pasa a desplegarse en el concepto ético de cupiditas, clave para enlazar el conatus con el apetito y el impulso potencial ontológico y, asimismo, para articular un eje que vaya desde la filosofía hasta la instauración de una República a través de la imaginación productiva. Una construcción al margen de toda trascendencia en la que, de existir el concepto de lo divino, se aplica al conjunto y unión de todas las potencias. El pensamiento de Spinoza se ha convertido, pues, íntegramente en pensamiento de superficie. 63

\section{Conclusiones}

La principal conclusión que queremos mostrar después de este recorrido es que toda configuración política del mando se sostiene sobre una visión finalista y trascendente, que convierte lo que puede ser el gozo de la construcción política en común en apología del poder. Para Spinoza, no hay ningún programa ni diseño que trascienda a la propia iniciativa de lo múltiple. Por ello afirma que «nadie podrá percibir rectamente lo que pretendo, a no ser que se guarde muy bien de confundir la potencia de Dios con la humana potencia, o derecho, de los reyes».64 Es decir, la potencia de la multitud no puede ser gobernada mediante mediaciones trascendentes o místicas.

Por ello, otra posible conclusión al respecto es que las figuras de la inmanencia y la univocidad pueden ser fecundas para construir una concepción materialista del ser y, al mismo tiempo, una ética de carácter horizontal que pueda sustentar una teo-

63 Op. Cit., pp. 212-220.

64 Baruch Spinoza. Ética. Op. Cit., p. 114. 
ría política democrática, alejada de concepciones trascendentes, en las que, en base a la búsqueda del individuo compuesto universal, o sujeto colectivo spinoziano, la potencia de unir prime en el ser humano por encima de los intereses individuales. Así, Spinoza se transforma en una enseñanza fundamental para poder ofrecer salidas y alternativas a los distintos poderes trascendentes y mediáticos, también ahora, en sus nuevas y continuas reestructuraciones.

Este es el camino que sigue Antonio Negri en su obra, y que le llevará a ver una línea política absolutista que parte de Hobbes y que se desarrolla -aunque con matices- en un reformismo continuo a lo largo del capitalismo hasta llegar al neoliberalismo vigente en la actualidad. Y esta línea es la que recoge y subsume la fuerza productiva propia de la potencia de la multitud dentro de las relaciones de producción clásicas del capitalismo y que llevan a la división en clases sociales contrarias entre sí y, consecuentemente, a la situación de explotación y enajenación de unos por parte de los otros. Es decir, es la guía materialista spinoziana la que orienta a Negri en su análisis político.

Del mismo modo, y siguiendo de nuevo un eje imaginario que una a Spinoza con Marx, Negri rechaza esta apropiación de la fuerza productiva y reivindica una apertura a la libre configuración de las potencias, que llevará consigo la libertad de las multitudes y, en último caso, su autodeterminación final.

¿Es esta una tentativa de imaginar la articulación de la potencia y el deseo con aquello que Spinoza solamente dejó esquematizado con el nombre de Democracia absoluta? 65 Seguramente ese ha sido uno de los caminos seguidos por el postoperaismo italiano -surgido a partir del movimiento de autonomía obrera en el que Negri participó en los años 70-, y uno de los objetivos del desarrollo que Negri y Hardt realizan de los conceptos de potencia y multitud en su trilogía Imperio, Multitud y Commonwealth, siguiendo de cerca la ontología política spinoziana y reivindicando su vigencia en el contexto político y social actual -a pesar de que, como vimos al respecto de la unión razón-deseo, exista algún punto oscuro en su interpretación, que quizás no profundice lo suficiente en el papel de la mens y el conocimiento.

Por su parte, Spinoza sí reivindica el papel del conocimiento como arma fundamental que también guíe a la acción, protegiendo a ésta de los excesos que se puede encontrar en el camino de la liberación humana. La sólida unión entre pensamiento y acción es entonces una de las enseñanzas fundamentales de la filosofía spinoziana, y puede ayudarnos también en los tiempos que vivimos, tantas veces plagados por uno solo de los polos del conjunto.

65 Baruch Spinoza. Tratado político. Op. Cit., cap. XI, pp. 220-224. 


\section{Referencias bibliográficas}

AlBIAC, G. La sinagoga vacía. Madrid: Hiperion, 1987.

BLOCH, Ernst. Avicena y la izquierda aristotélica. Madrid: Ciencia Nueva, 1966.

Deleuze, Gilles. Spinoza. Filosofia práctica. Madrid: Tusquets, 1984.

FERNÁNDEZ, Eugenio. "Articulación crítica de ontología y política en B. Spinoza». Revista de Filosofía [en línea]. $3^{\text {a }}$ época, vol. IX, núm. 15, 1996. Madrid: Servicio Publicaciones UCM, http://revistas.ucm.es/fsl/00348244/articulos/ RESF9696120097A.PDF, [Consulta: 20 de febr. 2009], ISSN: 1988-284x

GalCERÁn, Montserrat. Deseo (y) libertad Una investigación sobre los presupuestos de la acción colectiva. Madrid: Traficantes de sueños, 2009.

GeBhARdt, C. Spinoza. Buenos Aires: Losada, 1977.

Giancotti, Emilia. Studi su Hobbes e Spinoza. Napoli: Bibliopolis, 1995.

Gueroult, Martial. Spinoza, Dieu. Paris: Aubier Montaigne, 1974.

Martínez, Francisco José. Materialismo, idea de totalidad y método deductivo en Espinosa. Madrid: UNED, 1988.

Matheron, Alexandre. «Prefacio». En Negri, Antonio. L'anomalie sauvage. Paris: PUF, 1982.

Negri, Antonio. La anomalía salvaje. Barcelona: Anthropos, 1993.

Negri, Antonio. El poder constituyente. Madrid: Libertarias/Prodhufi, 1994.

Negri, Antonio. Spinoza subversivo. Variaciones (in)actuales. Madrid: Akal, 2000.

SPINOZA, Baruch. Tratado politico. Madrid: Alianza, 1986.

SPINOZA, Baruch. Tratado teológico-político. Madrid: Alianza, 1986.

SPINOZA, Baruch. Ética. Madrid: Alianza, 1987.

SpINOZA, Baruch. Correspondencia. Madrid: Alianza, 1988.

Tosel, Andre. Du materialisme de Spinoza. Paris: Kimé, 1994.

Abraham Rubín

Departamento de Filosofía moral y política

Universidad Nacional de Educación a Distancia

arubin@edu.xunta.es 